\title{
Integrated management of fire in Ilha Grande National Park, Brazil
}

\author{
Tersio Abel Pezenti ${ }^{1 *}$
}

${ }^{1}$ Chico Mendes Institute for Biodiversity Conservation (ICMBio) - Guaíra, Paraná
*Email to contact - tersio.pezenti@icmbio.gov.br

\begin{abstract}
Ilha Grande National Park - PNIG, located in Atlantic Forest biome and designated as Ramsar site, inserted in Brazilian territory, has a history of large fires in periods of 3 to 5 years. Although conservation unit - CU is in a semideciduous seasonal forest region, which is a fire-sensitive physiognomy occurs, the predominance of the pioneer vegetation of Influence Fluoride Lacustre, so-called floodplains, in more than $80 \%$ of its area. After decades of combat attempts, most often frustrated, and with recognition so much of management, community ( fishermen, beekeepers, islanders ), of which: Large fires in critical and uncontrolled times tend to cause greater damage and be difficult to combat and control; The floodplain vegetation has a visible resilience going into regrowth shortly after the passage of the flames; Fires with more than 30,000 ha ( around $60 \%$ of the unit ) have already been recorder in only one event. Considering the factors mentioned above, all combat difficulties, characteristics of flammability and rapid recovery of lowplains versus the sensitivity of semideciduous forest, we chose to adopt integrated fire management ( MIF ), which has for main management objectives avoid large fires and protect more sensitive environments and reduce the biomass of pioneer vegetation with Fluoride Lacustre Influence for flames do not enter the restingas and riparian forest composed of Semideciduous seasonal forest that are sensitive and has as much slower response than pioneers. To achieve these objectives, prescribed burns are being planned, initiated in 2018 and continued in 2019, in search of a more effective response to fires. Thus, the management of fire in CU life to the preservation of the ecosystem with prescribed burnings in times with climatic characteristics conducive to forest preservation and easy propagation in lowland. This approach, due to the complexity of fires in the park area, is being developed with the support of several partners and dialogue with the users of the territory, public authorities and brought to the knowledge of the scientific community so that they can be initiated research on the relationship with fauna, flora, soils and gas emission, which help park management find the best conservation results in fire management.
\end{abstract}

Keywords: Fire Management, Prescribed Burning, National Park, Atlantic Forest, Floodplain. 